\title{
Design of a Microcontroller Based Automatic Voltage Stabilizer with Toroidal Transformer
}

\author{
Thet Htun Aung \\ Department of Electrical Power Engineering \\ Mandalay Technological University \\ Myanmar
}

\begin{abstract}
Every electrical and electronic appliance is designed to work perfectly at a certain input voltage. In Myanmar, household electrical and electronic appliances are designed to work properly at $220 \mathrm{VAC}, 50 \mathrm{~Hz}$ and most of the times the voltage supplied from distribution companies are as low as 130VAC making this appliances to work under threat of low voltage supply. This low supply voltage causes these appliances to malfunction and in most cases damage them. Since the electric power supply/distribution companies are unable to provide the consistent adequate voltage level (220VAC) demanded by these sensitive appliances, therefore there is need for consumers to protect the appliances from damage and ensure their safe operation, hence the use of automatic voltage stabilizers to improve the situation. In this research work, a PIC16F877A microcontroller was programmed to monitor the input voltage from distribution companies and if voltage level is between $130 \mathrm{VAC}$ and $250 \mathrm{VAC}$, it gives a constant output voltage of nearly $220 \mathrm{VAC}$ required by the appliance. The model parameter calculated from the design information.
\end{abstract}

Keywords - Myanmar, Household Electrical, Stabilizer, Input And Output Voltage, Electric Power Supply, Distribution, Microcontroller.

\section{INTRODUCTION}

The development of any country is largely hinged on the availability of undisturbed and regulated power supply. In Myanmar, electricity is generated by turbine driven synchronous generators at $50 \mathrm{~Hz}$ at a standard minimum voltage of $11 \mathrm{kV}$. The generated voltage is then stepped up to the primary or secondary Grid voltage of $132 \mathrm{kV}$ to reduce power losses during transmission. The generated power then travels from the generating stations to the point of utilization via high voltage Transmission lines, most of which are suspended overhead. However due to the uneven power demand at the load end and the complexity of the consumer network, a third party is required to ensure that the generated electricity is properly distributed according to the load demand, while taking into consideration the necessary geographic and economic factors as they affect the overall socioeconomic growth of the nation. In Distribution, electrical power is stepped down at distribution sub-stations of various levels to a final voltage of $400 \mathrm{~V}$ (phase to phase) and $230 \mathrm{~V}$ (phase to neutral) which is directly consumed by most electrical load. Voltage is the most important parameter in electrical power [1] system and it is necessary to be maintained a constant output voltage because, it is the driving force that pushes current through the conductor. Voltage stability is vital for safety and optimal performance of electrical appliances. Most electrical appliances are designed for optimal operation, maximum length of service and safety if the power rating of the appliance is maintained.
The automatic voltage stabilizer presented in this research aim at designing a suitable Automatic Voltage Stabilizer rated $15 \mathrm{kVA}$ with output $220 \mathrm{VAC}$, when the input voltage is varying between $130 \mathrm{VAC}$ and $250 \mathrm{VAC}$.

\section{Mathematical EQUations of TOROIDAL TRANSFORMER}

The rating of the servo motor automatic voltage stabilizer is mainly depended on the transformer rating. The circuit diagram of the servo motor automatic voltage stabilizer including variable autotransformer. The simplest device for regulating the voltage applied to a load is the variable auto-transformer. One of the best known types is the "Variac". The core consists of a deep stack of ring-shaped laminations. The insulation is removed from a circular track around the upper horizontal face of the winding and a carbon brush carried on a rotating arm makes contact with any desired turn on the winding. For the input fluctuation $-40 \%,+10 \%$ toroidal transformer must be withstand the variation of the maximum input voltage is $242 \mathrm{~V} \approx 250 \mathrm{~V}$ and the minimum input voltage is $132 \mathrm{~V} \approx 130 \mathrm{~V}$. The output voltage must be nearly $220 \mathrm{~V}$. Variable transformer type of this AVS is toroidal transformer. The capacity of automatic voltage stabilizer is $15 \mathrm{kVA}$ (single-phase). The output voltage regulation is $\pm 5 \%$.

\section{A. Design Equation}

Equations such as e.m.f. equation, e.m.f. per turn in terms of output and output equation are needed to design 
of the magnetic circuit (main dimensions of core, yoke and window).

\section{B. E.M.F. Equation}

When the alternating voltage is applied across the primary of the transformer, it takes a magnetizing current and a flux; $\varphi$ is established in the transformer core. The flux, $\varphi$ is uniformly distributed over the transformer core section and is linked with all the turns of primary and secondary windings. The main flux, $\varphi$ established in the core is alternating in nature.

Hence an e.m.f. is induced in the primary winding, due to the change of main flux, which is given by,

$$
\begin{aligned}
& \mathrm{e}_{1}=-\mathrm{N}_{1} \\
& \varphi=\varphi_{\mathrm{m}} \cos \omega \mathrm{t} \\
& \mathrm{e}_{1}=\frac{-\mathrm{N}_{1} \mathrm{~d}\left(\varphi_{\mathrm{m}} \cos \omega \mathrm{t}\right)}{\mathrm{dt}}=\mathrm{N}_{1} \omega \varphi_{\mathrm{m}} \sin \omega \mathrm{t} \\
& \mathrm{E}_{1}=4.44 \mathrm{f} \mathrm{N}_{1} \varphi_{\mathrm{m}} \text { volts } \\
& \mathrm{E}_{1}=4.44 \mathrm{f} \mathrm{N}_{1} \mathrm{~B}_{\mathrm{m}} \mathrm{A}_{\mathrm{i}}\left(\text { where } \varphi_{\mathrm{m}}=\mathrm{B}_{\mathrm{m}} \mathrm{A}_{\mathrm{i}}\right) \\
& \text { Induced e.m.f. in secondary winding, } \\
& \mathrm{E}_{2}=4.44 \mathrm{f} \mathrm{N}_{2} \mathrm{~B}_{\mathrm{m}} \mathrm{A}_{\mathrm{i}} \text { volts } \\
& \text { e.m.f. per turn, } \\
& \mathrm{E}_{\mathrm{t}}=4.44 \mathrm{f} \mathrm{B}_{\mathrm{m}} \mathrm{A}_{\mathrm{i}} \\
& \text { For } \mathrm{E} \cdot \mathrm{M} . \mathrm{F} \mathrm{per} \mathrm{Turn}, \\
& \mathrm{E}_{\mathrm{t}}=4.44 \mathrm{f} \varphi_{\mathrm{m}} \\
& \text { K.V.A rating per phase, } \\
& \mathrm{E}_{\mathrm{t}}=\mathrm{V} \times \mathrm{I} \times 10^{-3}=\frac{\mathrm{V}}{\mathrm{N}} \times \mathrm{IN} \times 10^{-3} \\
& \quad=\mathrm{E}_{\mathrm{t}} \times \mathrm{IN} \times 10^{-3}
\end{aligned}
$$

The ratio of cross-sectional area of the core and the copper area of the windings will be constant for a particular transformer i.e.

$$
\frac{\mathrm{A}_{\mathrm{i}}}{\mathrm{A}_{\mathrm{c}}}=\text { constant }
$$

Cross sectional area of core,

$$
\begin{aligned}
\mathrm{A}_{\mathrm{i}} & =\frac{\varphi_{\mathrm{m}}}{\mathrm{B}_{\mathrm{m}}} \text { or } \\
\mathrm{A}_{\mathrm{i}} & =\frac{\sqrt{\mathrm{P}}}{5.58} \mathrm{sq} \text { in }
\end{aligned}
$$

Copper area of the windings,

$$
\begin{aligned}
& \mathrm{A}_{\mathrm{c}}=\mathrm{aN}=\frac{\mathrm{I}}{\delta} \times \mathrm{N} \\
& \frac{\mathrm{A}_{\mathrm{i}}}{\mathrm{A}_{\mathrm{c}}}=\frac{\varphi_{\mathrm{m}}}{\mathrm{IN}} \times \frac{\delta}{\mathrm{B}_{\mathrm{m}}}
\end{aligned}
$$

As current density, $\delta$ and flux density, $B_{m}$ is nearly constant,

$$
\frac{\varphi_{\mathrm{m}}}{\mathrm{IN}}=\text { constant }=\mathrm{r}
$$

Substituting for IN from Equation 12 into Equation 8,

$$
\begin{aligned}
& \frac{\mathrm{kVA}}{\text { phase }}=\mathrm{E}_{\mathrm{t}} \times \frac{\varphi_{\mathrm{m}}}{\mathrm{r}} \times 10^{-3}(\text { or }) \\
& \varphi_{\mathrm{m}}=\frac{\left(\frac{\mathrm{kVA}}{\mathrm{phase}}\right) \times \mathrm{r}}{\mathrm{E}_{\mathrm{t}}} \times 10^{3}
\end{aligned}
$$

Substituting for $\varphi_{\mathrm{m}}$ from Equation 13 into Equation 7,

$$
\begin{aligned}
& \mathrm{E}_{\mathrm{t}}=4.44 \mathrm{f} \times \frac{\left(\frac{\mathrm{kVA}}{\text { phase }}\right) \times \mathrm{r}}{\mathrm{E}_{\mathrm{t}}} \times 10^{3} \\
& \mathrm{E}_{\mathrm{t}}^{2}=\left(4.44 \mathrm{fr} \times 10^{3}\right) \times \frac{\mathrm{kVA}}{\text { phase }}
\end{aligned}
$$

e.m.f. per turn,

$$
\begin{aligned}
\mathrm{E}_{\mathrm{t}} & =\frac{4.44 \mathrm{~B}_{\mathrm{m}} \mathrm{N}_{\mathrm{e}} \mathrm{f} \mathrm{\textrm {A } _ { \mathrm { i } }}}{10^{8}} \text { volt } \\
\mathrm{E}_{\mathrm{t}} & =\mathrm{K} \sqrt{(\mathrm{kVA} / \text { phase })}
\end{aligned}
$$

Where $\mathrm{K}=\sqrt{4.44 \mathrm{f} \mathrm{r} \times 10^{3}}$

In order to utilize equation 12 , for finding out the e.m.f. per turn, the value of the factor, $\mathrm{K}$ is needed. And then, the turns per volt will be got.

$$
\text { Turns per volt, } \mathrm{N}_{\mathrm{e}}=\frac{\mathrm{E}_{\mathrm{t}} \times 10^{8}}{4.44 \mathrm{~B}_{\mathrm{m}} \mathrm{f} \mathrm{A} \mathrm{A}_{\mathrm{i}}}
$$

\section{Factor $K$}

Factor, K which basically depends upon the ratio of cross sectional area of core to the copper section of the windings, will be different for two types of transformers i.e. core and shell. The value of factor $\mathrm{K}$ with respect to transformer type is shown in Table I.

\section{TABLE I. CONSTANT K WITH RESPECT TO} TRANSFORMER TYPE

\begin{tabular}{|l|c|}
\hline \multicolumn{1}{|c|}{ Type } & K ( Factor) \\
\hline (1) Single phase core & $0.75-0.8$ \\
\hline (2) Single phase shell & $1.0-1.1$ \\
\hline (3) Three phase core (power) & $0.6-0.65$ \\
\hline (4) Three phase core (distribution) & $0.45-0.5$ \\
\hline (5) Three phase shell & $1.2-1.3$ \\
\hline
\end{tabular}

\section{Stacking Factor}

To get the required core section, the transformer core is prepared by stacking together thin sheets of laminations. These laminations are insulated on both sides usually by spray of varnish. That, the assembled core includes the area of insulation as well. The gross core section $A_{g i}$, is related with the net core section, $A_{i}$, by a factor $\mathrm{K}_{\mathrm{s}}$ called stacking factor.

$$
\begin{aligned}
& \text { Thus, } \mathrm{A}_{\mathrm{i}}=\mathrm{K}_{\mathrm{s}} \mathrm{A}_{\mathrm{gi}} \\
& \mathrm{K}_{\mathrm{s}}=\text { stacking factor, usually value is } 0.85 \sim 0.9 \text {. }
\end{aligned}
$$




\section{E. Flux Density $\left(\boldsymbol{B}_{m}\right)$}

The voltage equation as well as output equation indicates that the higher value of flux density $\mathrm{B}_{\mathrm{m}}$ is chosen, the core area Ai reduces. This will reduce the diameter of circumcircle thereby reducing the length of mean turn. The choice of $\mathrm{B}_{\mathrm{m}}$ will also depends upon the type, service conditions of the transformer. It has already been pointed out that a distribution transformer should be designed for lower iron losses giving good all-day efficiency. Therefore, for distribution transformer comparatively lower flux density is assumed.

Using hot rolled silicon steel

$\begin{array}{ll}\text { Power transformers } & -1.2 \text { to } 1.4 \text { Tesla } \\ \text { Distribution transformers } & -1.1 \text { to } 1.3 \text { Tesla }\end{array}$

Using cold rolled grain oriented silicon steel

$\begin{array}{ll}\text { Power transformers } & -1.5 \text { to } 1.7 \text { Tesla } \\ \text { Distribution transformers } & -1.4 \text { to } 1.5 \text { Tesla }\end{array}$

Lower values should be used for small rating transformers.

\section{iII. Calculation of Toroidal TRANSFORMER}

According to Equation 1 to Equation 17, $15 \mathrm{kVA}$ rating of the variable transformer is designed in this research.

\section{Core Design of Toroidal Transformer}

$$
\begin{aligned}
\text { Cross section area of iron core, } & =\frac{\sqrt{15 \times 10^{3}}}{5.58} \\
& =21.949 \mathrm{in}^{2} \\
& =141.606 \mathrm{~cm}^{2} \\
\text { Assume stacking factor }\left(\mathrm{k}_{\mathrm{s}}\right) & =0.9
\end{aligned}
$$

$$
\begin{aligned}
\text { Net-cross sectional area of iron core, } & =\frac{141.606}{0.9} \\
& =157.34 \mathrm{~cm}^{2}
\end{aligned}
$$

For cold rolled grained oriented silicon steel,

Flux density, $\quad \mathrm{B}_{\mathrm{m}} \quad=1.4 \sim 1.5 \mathrm{~Wb} / \mathrm{m}^{2}$

Assume flux density, $\mathrm{B}_{\mathrm{m}}=1.4 \mathrm{~Wb} / \mathrm{m}^{2}$

Turns per volt,

At $\mathrm{K}=0.8$,

$\mathrm{E}_{\mathrm{t}}=0.8 \sqrt{15}=3.098$

Turns per volt, $\quad \mathrm{N}_{\mathrm{e}}=\frac{10}{21.949}=0.5$ turns $/$ volt

Since the form of the toroidal type transformer is a circular ring, the circumference condition, the inner diameter, the outer diameter, height of the core and the width place take by the winding will be considered first.

Width of the ring face, $\mathrm{A}=\sqrt{157.34}=12.543 \mathrm{~cm}$

The ratio of the B/A must have 1.5 2 times. In $15 \mathrm{kVA}$ autotransformer design, if $\mathrm{A}=9 \mathrm{~cm}$, the height of the core, B, must be $17.483 \mathrm{~cm}$.

Assume inner diameter $\left(\mathrm{d}_{\mathrm{i}}\right) \quad=12 \mathrm{~cm}$

$$
\begin{array}{ll}
\text { Inner radius }\left(\mathrm{r}_{\mathrm{i}}\right) & =6 \mathrm{~cm} \\
\text { Outer radius }\left(\mathrm{r}_{0}\right) & =\mathrm{r}_{\mathrm{i}}+\mathrm{A}=15 \mathrm{~cm}
\end{array}
$$$$
\text { So, outer diameter }\left(\mathrm{d}_{\mathrm{o}}\right)=2 \mathrm{r}_{0}=30 \mathrm{~cm}
$$

Section view of toroidal autotransformer is shown in Fig. 1.

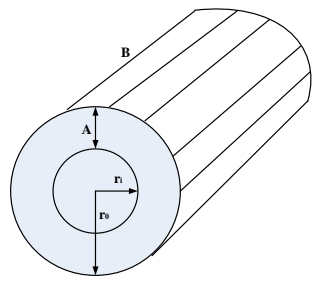

Figure 1. Section View of Toroidal Autotransformer

Winding Design of Toroidal Transformer

In winding design,

$\mathrm{S}=15 \mathrm{kVA}$

$\mathrm{V}=250 \mathrm{~V}$

$\mathrm{f} \quad=50 \mathrm{~Hz}$

Assume Efficiency, $\eta=0.9(90 \%)$

Maximum current rating of the transformer,

I $=\frac{15 \times 10^{3}}{250 \times 0.9}=66.67 \mathrm{~A}$

So, S.W.G (6) will be chosen.

From standard wire gauge table,

Net cross-section area $\quad=109.092 \mathrm{~mm}^{2}$

Diameter of bare conductor $\quad=11.7856 \mathrm{~mm}$

Length for a turn $\quad=2(\mathrm{~A}+\mathrm{B})$

$=2(9+17.483)$

$=52.966 \mathrm{~cm} \approx 53 \mathrm{~cm}$

Total length for a winding $=$ mean length for a turn $\times$ number of turns $=53 \times 125=6625 \mathrm{~cm}$

From standard wire gauge table,

For S.W.G (6),

$1000 \mathrm{ft}-111.6 \mathrm{lbs}$

$30480 \mathrm{~cm}-111.6 \mathrm{lbs}$

$6625 \mathrm{~cm}-$ ?

$$
=24.25 \mathrm{lbs} \approx 25 \mathrm{lbs}
$$

Therefore, $25 \mathrm{lbs}$ of the winding will be needed for the SWG (6) of the toroidal transformer. Wiring diagram of toroidal autotransformer is shown in Fig. 2.

$\begin{aligned} \text { Number of winding turns from } \mathrm{P} \text { to } \mathrm{N} & =250 \times 0.5 \\ & =125 \text { turns } \\ \text { Number of winding turns from A to } \mathrm{N} & =220 \times 0.5 \\ & =110 \\ \text { Number of winding turns from A to } \mathrm{P} & =15 \text { turns }\end{aligned}$

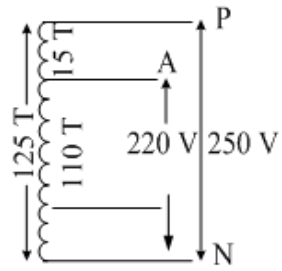

Figure 2. Wiring Diagram of Toroidal Autotransformer 
Current rating of each winding, $\mathrm{I}_{\text {each }}=\frac{66.67}{125}=0.533$

Current density, $\delta=2.00$ to $2.5 \mathrm{~A} / \mathrm{mm}^{2}$

Assume, current density, $\delta=2 \mathrm{~A} / \mathrm{mm}^{2}$

Cross sectional area of each winding,

$\mathrm{A}=\frac{0.533}{2}=0.2665 \mathrm{~mm}^{2}$

$\pi r^{2}=0.2665$

$\mathrm{r}=0.287 \mathrm{~mm}$

Diameter of each winding, $\mathrm{d}=2 \times \mathrm{r}$

$\begin{aligned} & =0.574 \mathrm{~mm} \\ \text { Diameter of all winding, } \mathrm{d}_{1} & =0.574 \times 125\end{aligned}$

$=71.75 \mathrm{~mm}$

Circumference of all winding $=\pi \times \mathrm{d}_{1}=225 \mathrm{~mm}$

Diameter of core, $\quad \mathrm{d}_{2} \quad=9 \mathrm{~cm}=90 \mathrm{~mm}$

Circumference of core $\quad=\pi \times \mathrm{d}_{2}=282.74 \mathrm{~mm}$

Spacing of winding $\quad=282.74-225$

$=57.74 \mathrm{~mm}$

Spacing of each winding

$=\frac{57.74}{125}=0.462 \mathrm{~mm}$

Spacing of each winding $=\frac{0.462}{\pi}=0.15 \mathrm{~mm}$

The calculated values of toroidal autotransformer are shown in Table II

TABLE II. Detailed Design ShEET For TOROIDAL AUTOTRANSFORMER

\begin{tabular}{|l|l|l|l|}
\hline Description & Symbol & Unit & $\begin{array}{l}\text { Designed } \\
\text { values }\end{array}$ \\
\hline kVA Rating & $\mathrm{P}$ (or) $\mathrm{S}$ & $\mathrm{kVA}$ & 15 \\
\hline Cross sectional area & $\mathrm{A}_{\mathrm{i}}$ & $\mathrm{cm}^{2}$ & 141.606 \\
\hline Net cross sectional area & $\mathrm{A}_{\mathrm{gi}}$ & $\mathrm{cm}^{2}$ & 157.34 \\
\hline Turn per volt & $\mathrm{N}_{\mathrm{e}}$ & $\mathrm{T} / \mathrm{V}$ & 0.5 \\
\hline Width of ring face of core & $\mathrm{A}$ & $\mathrm{cm}$ & 9 \\
\hline Height of core & $\mathrm{B}$ & $\mathrm{cm}$ & 17.483 \\
\hline Inner diameter & $\mathrm{d}_{\mathrm{i}}$ & $\mathrm{cm}$ & 12 \\
\hline Inner radius & $\mathrm{r}_{\mathrm{i}}$ & $\mathrm{cm}$ & 6 \\
\hline Outer diameter & $\mathrm{d}_{\mathrm{o}}$ & $\mathrm{cm}$ & 30 \\
\hline Outer radius & $\mathrm{r}_{\mathrm{o}}$ & $\mathrm{cm}$ & 15 \\
\hline Current & $\mathrm{I}$ & $\mathrm{A}$ & 66.67 \\
\hline Number of turns & $\mathrm{N}$ & - & 125 \\
\hline Conductor area & $\mathrm{a}$ & $\mathrm{mm}$ & 109.092 \\
\hline Bare diameter & $\mathrm{b}$ & $\mathrm{mm}$ & 11.7856 \\
\hline Length for a turn & - & $\mathrm{cm} / \mathrm{turn}$ & 53 \\
\hline Total length for a winding & - & $\mathrm{cm}$ & 6625 \\
\hline Pounds of the winding & - & $\mathrm{lbs}$ & 25 \\
\hline Current of each winding & $\mathrm{I}_{\text {each }}$ & $\mathrm{A}$ & 0.533 \\
\hline $\begin{array}{l}\text { Cross sectional area of each } \\
\text { winding }\end{array}$ & $\mathrm{A}$ & $\mathrm{mm}{ }^{2}$ & 0.2665 \\
\hline Diameter of each winding & $\mathrm{d}$ & $\mathrm{mm}$ & 0.574 \\
\hline Diameter of all winding & $\mathrm{d}_{1}$ & $\mathrm{~mm}$ & 71.75 \\
\hline Circumference of all winding & - & $\mathrm{mm}$ & 225 \\
\hline Circumference of core & - & $\mathrm{mm}$ & 282.74 \\
\hline Spacing of winding & - & $\mathrm{mm}$ & 57.74 \\
\hline Spacing of each winding & - & $\mathrm{mm}$ & 0.15 \\
\hline & & & \\
\hline
\end{tabular}


$2.55 \mathrm{~V}$ for phase $\mathrm{R}, 3.73 \mathrm{~V}$ for phase $\mathrm{Y}$ and $2.96 \mathrm{~V}$ for phase B.

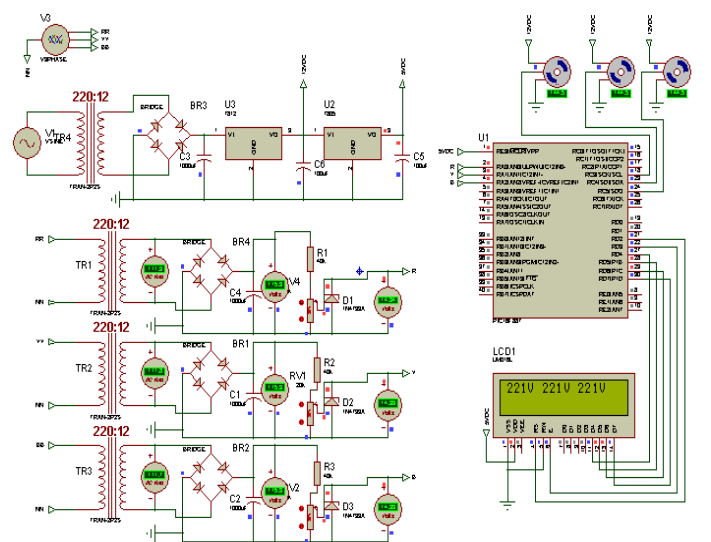

Figure 5. Simulation Result of AVS Controller in Stable Condition

During the over voltage condition, the input voltage of the stabilizer is higher than output voltage. In this condition, the motor drive in reverse direction as to decrease the stabilizer output voltage to the $220 \mathrm{~V}$. Figure 7 shows over voltage condition of servo control system by using Proteus Software. In this figure, the input voltage of microcontroller is $4.52 \mathrm{~V}$ for phase $\mathrm{R}, 4.69 \mathrm{~V}$ for phase $\mathrm{Y}$ and $4.89 \mathrm{~V}$ for phase $\mathrm{B}$.

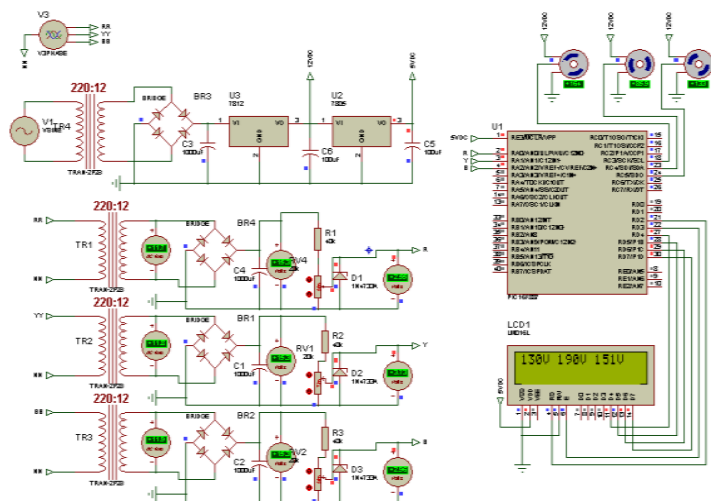

Figure 6. Simulation Result of AVS Controller in Under Voltage Condition

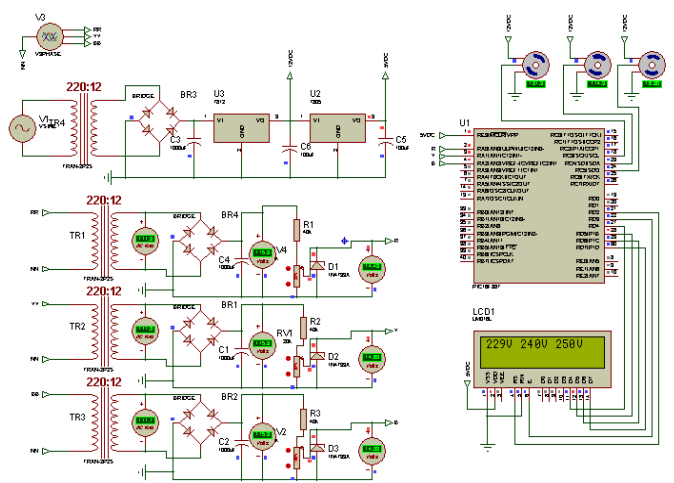

Figure 7. Simulation Result of AVS Controller in Over Voltage Condition

\section{VI.TEST RESULTS OF STABILIZER OUTPUT AT DIFFERENT INPUT VOLTAGES}

Table II shows the direction of servo motor depending on the variable input voltage to get nearly the stable output voltage $220 \mathrm{~V}$.

TABLE II. FoR LOW VOLTAGE UP TO - $40 \%$ AND HigH VOLTAGE UP TO $+10 \%$, ANGLE DISPLACEMENT WITH RESPECT TO Voltage FluCtuation

\begin{tabular}{|c|c|c|c|c|}
\hline $\begin{array}{c}\text { Input } \\
\text { voltage }\end{array}$ & $\begin{array}{c}\text { Different } \\
\text { voltage }\end{array}$ & $\begin{array}{c}\text { Number } \\
\text { of turns }\end{array}$ & $\begin{array}{c}\text { Clockwise } \\
\text { direction }\end{array}$ & $\begin{array}{c}\text { Output } \\
\text { voltage }\end{array}$ \\
\hline 130 & -90 & 45 & $164^{\circ}$ & 218.31 \\
\hline 140 & -80 & 40 & $148^{\circ}$ & 218.43 \\
\hline 150 & -70 & 35 & $133^{\circ}$ & 218.53 \\
\hline 160 & -60 & 30 & $127^{\circ}$ & 218.63 \\
\hline 170 & -50 & 25 & $111^{\circ}$ & 218.71 \\
\hline 180 & -40 & 20 & $94.5^{\circ}$ & 218.78 \\
\hline 190 & -30 & 15 & $85.8^{\circ}$ & 218.84 \\
\hline 200 & -20 & 10 & $68.4^{\circ}$ & 218.90 \\
\hline 210 & -10 & 5 & $53.3^{\circ}$ & 221.05 \\
\hline 220 & - & - & $45.1^{\circ}$ & 221.00 \\
\hline 230 & +10 & 5 & $31.8^{\circ}$ & 221.05 \\
\hline 240 & +20 & 10 & $14.7^{\circ}$ & 221.09 \\
\hline 250 & +30 & 15 & $6.72^{\circ}$ & 221.14 \\
\hline
\end{tabular}

In this research, when the voltage fluctuation is lower than $130 \mathrm{~V}$ and higher than $250 \mathrm{~V}$, the servo control automatic voltage stabilizer is automatically shut down and does not operate in this situation. The servo motor automatic voltage stabilizer will nearly produce the stable output voltage $220 \mathrm{~V}$.

\section{Conclusions}

Test outcome shows that the output voltage remains virtually constant at varying input voltage. However, at extremely low voltages below $130 \mathrm{~V}$ there was no output voltage because the switching device is not even activated. On the other hand, at voltages beyond $250 \mathrm{~V}$ the system protection is activated and no output voltage. Therefore the research has made it possible for the device to operate from as low as $130 \mathrm{~V}$. The primary objective of this work which was to improve the performance of conventional AC voltage stabilizer was achieved. The work was designed in consideration with some factors such as economy, availability of components, efficiency, compatibility, portability and durability.

\section{ACKNOWLEDGMENT}

The author greatly expresses to his thanks to all persons whom will concern to support in preparing this research.

\section{REFERENCES}

[1] BartloiejBelko, M. C.: The Conception and Implementation of Control System for Servo Motor with Application of Local Area Network, Cracow, (2010).

[2] Metrel: Single-phase Built-in Variable Transformer, Three-phase Built-in Variable Transformer, Motor 
Driven Variable Transformer, Desk top Variable Transformer, (2009). http://www.netrel.si

[3] Hans Beijher: Output Transformers and Magnetic Formulas, Prentice-Hall, Noord-Holland, Netherlands, (2004).

[4] Matt Ruff: Servomotor Control Application, Freescal Semiconductor Inc., Japan, (2004).

[5] Biswanath Paul: Industrial Electronics and Control, Prentice-Hall of Private Limited, India, (2001).

[6] Chuck McManis: Servo Basic, Omron Asia Pacific Pte, Ltd., Korea, (2000).

[7] Mark Readman: Motors, Seimens Company, London, (1997).

[8] Bhopal: Design of Electrical Machines, Standard Publisher Distributors, 4th Ed., 1705-E, NalSarak, DELHI-110006, (1996).

[9] Patchett, G.N.: Automatic Voltage Regulators and Stabilizers, Sir Isaac Pitman and Sons Ltd., 2nd Ed., Canada, (1954). 